\title{
ANALISA SEMIOLOGI PESAN MORAL PADA FILM "BEAUTY AND THE BEAST LIVE ACTION"
}

\author{
Juanna ${ }^{1)}$, Sholihul Abidin ${ }^{2)}$ \\ 1) Prodi Ilmu Komunikasi, Universitas Putera Batam \\ ${ }^{2)}$ Prodi Ilmu Komunikasi, Universitas Putera Batam \\ Email ;1) juanna_2423@yahoo.com,
}

\begin{abstract}
"Beauty and The Beast Live Action" movie is a re-make film of the original version with the same title in 1991. As a romantic themed fiction show, it's no wonder that the film managed to tie the audience emotionally, so the audience can sense that they are part of the film as long as he/she watched the movie. By the time the film finishes, there will be at least a meaning or moral message that can be taken from a movie, which is composed of signs containing a moral message. Overall, the movie Beauty and The Beast Live Action gives a moral message that we should not judge a person just from his appearance alone, because the most important is the kindness of the person. However, if we look closely at the signs contained in each scene, there are still some moral messages beyond the theme of the film that we can take through semiological analysis, using qualitative research methods. This research uses Charles Sanders Peirce's semiology theory which divides the mark into three categories namely icons, indexes and symbols in creating meaning, which will then be summed up into a moral message. The object of research investigated is some snippets of scenes in the film that will be drawn conclusions of moral messages based on semiology analysis, so that ultimately obtained the results of research on what moral messages contained in every scene of the film and also that the moral message is not only obtained from the entire film alone, but also through each scene cut.
\end{abstract}

Keywords: Semiology, Moral Message, Film, audio visualmessage

\section{PENDAHULUAN}

Film merupakan bentuk seni kompleks dan media komunikasi yang pengaruhnya dapat menjangkau seluruh segmen sosial masyarakat. Film tidak hanya merupakan media hiburan saja, tetapi film juga memberikan semacam rasa kehadiran dan kedekatan dengan suatu dunia yang tidak tertandingi dengan tempat lain, seperti dunia khayalan atau dunia yang tidak terbayangkan. Film merupakan karya sastra dari sinematografi. Sinematografi adalah kata serapan dari bahasa inggris cinematography yang berasal dari bahasa latin kinema yang artinya "gambar" (Yoyon Mudijiono, 2011).

Film dapat memberikan pengaruh yang sangat besar sekali pada jiwa manusia (penonton). Dalam suatu proses menonton sebuah film, terjadi suatu gejala yang disebut oleh ilmu jiwa sosial sebagai identifikasi psikologi (Taufik, 2016).

Ada banyak sekali genre film yang di tayangkan di bioskop maupun televisi. Salah satu genre film yang cukup banyak di minati adalah film fantasi, yaitu jenis film fiksi yang di karang dan mengundang imajinasi penonton, sehingga pada saat menikmati film, 
penonton seolah-oleh "keluar" dari kehidupan normal dan menuju negri khayalan. Film fantasi sendiri terdiri dari beberapa macam, seperti fantasi aksi, fantasi sihir, maupun animasi. Salah satu film fantasi yang tayang pada tahun 2017 adalah film Beauty and The Beast yang diadaptasi dari film animasi pada tahun 1992 dan kali ini di perankan langsung oleh manusia asli. Dalam dunia perfilman, biasanya disebut versi live-action. Tayangan sejenis ini akan membuat penonton seolaholah dapat menonton ulang film rekaan Disney ini secara lebih nyata.

Sebagai film yang awalnya merupakan film anak-anak, tentunya ada nilai moral yang diajarkan dalam suatu film, termasuk film Beauty and The Beast. Nyatanya, film ini terkenal dengan pesan moralnya, yaitu "kita tidak boleh memandang orang lain hanya dari penampilannya saja" atau "cinta sejati tidak memandang penampilan yang buruk rupa". Tetapi jika lebih di teliti lagi, sebenarnya ada beberapa pesan moral yang dapat kita analisa dari beberapa scene dalam film ini, dengan menggunakan analisis semiologi yang merupakan salah satu teori dalam ilmu komunikasi.

Semiologi adalah ilmu tentang tandatanda. Studi tentang tanda dan segala yang berhubungan dengannya, cara berfungsinya, hubungannya dengan tanda-tanda lain, pengirimannya dan penerimaannya oleh mereka yang menggunakannya. Semiotik mempelajari sistem-sistem, aturan-aturan, konvensi-konvensi yang memungkinkan tanda-tanda tersebut mempunyai arti (Kriyantono, 2006). Film umumnya dibangun dengan banyak tanda. Tandatanda itu termasuk berbagai sistem tanda yang bekerja sama dengan baik dalam upaya mencapai efek yang diharapkan untuk dapat di tangkap oleh penonton sebagai pesan moral. Pesan moral dari sebuah film bukan hanya dilihat berdasarkan akhir dari kisah cerita film tersebut saja, karena pesan moral sebuah film biasanya tidak hanya di gambarkan secara langsung, tetapi dapat juga secara tidak langsung.

Melihat masih banyak pesan-pesan moral yang dapat di analisa dari film Beauty and The Beast Live Action, maka penulis tertarik untuk melakukan penelitian berjudul "Analisa Semiologi Terhadap Film Beauty and The Beast Live Action" ini. Ketertarikan penulis untuk melakukan penelitian ini di dasari oleh keyakinan bahwa pesan sebuah film tidak cukup diukur hanya berdasarkan akhir kisah cerita saja, melainkan juga tersirat dalam setiap cuplikan adegan dalam film tersebut.

\section{KAJIAN PUSTAKA}

Sebagai salah satu bentuk seni yang menarik dan sangat mudah untuk didapatkan, film memiliki tujuan untuk mempengaruhi banyak orang di dalam suatu masyarakat melalui pesan dan gambarnya. 
Ketika beberapa film bertujuan untuk mendidik penontonnya, ada juga yang hanya ingin menghibur. Sedangkan banyak juga yang mencoba untuk melakukan keduanya. Film biasanya ingin mendidik penontonnya dengan mengajarkan pelajaran moral (Ikrommullah, 2015).

Semiologi adalah ilmu yang mempelajari tentang tanda-tanda. Tandatanda atau signs adalah basis dari seluruh komunikasi (Littlejohn, 1996:64). Manusia dengan perantaraan tanda-tanda dapat melakukan komunikasi dengan sesamanya. Banyak hal bisa dikomunikasikan di dunia ini.

Penelitian ini menggunakan teori semiologi menurut Charles Sanders Peirce. Pierce menjelaskan model semiologi secara sederhana yang terkenal, yaitu segitiga bermakna.

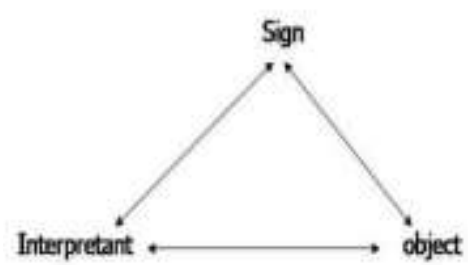

Gambar 2.1.1.Segitiga Bermakna

Sebuah tanda adalah sesuatu yang bagi seseorang mewakili sesuatu di dalam beberapa hal atau kapasitas tertentu. Tanda menuju pada seseorang, yang artinya menciptakan di dalam benak orang tersebut tanda yang sepadan, atau mungkin juga tanda yang lebih sempurna. Tanda yang tercipta di benak tersebut di sebut interpretant atau hasil interpretasi dari tanda yang pertama. Tanda mewakili sesuatu, yaitu objeknya

Charles Sanders Peirce (Fiske, 2014) merumuskan bagaimana kemunculan sebuah maksa berdasarkan tanda. Ia memecahkan rincian sebuah tanda yang terdiri dari ikon (icon), indeks (Index) dan simbol (symbol), yang dijelaskan sebagai berikut:

1. Ikon: suatu tanda di mana hubungan antara tanda dan acuannya berupa hubungan berupa kemiripan. Jadi ikon adalah bentuk tanda yang dalam berbagai bentuk menyerupai objek dari tanda tersebut. Patung kuda adalah ikon dari seekor kuda.

2. Indeks: suatu tanda di mana hubungan antara tanda dan acuannya timbul karena ada kedekatan eksistensi. Jadi indeks adalah suatu tanda yang mempunyai hubungan langsung (kausalitas) dengan objeknya. Asap merupakan indeks dari adanya api.

3. Lambang: suatu tanda dimana hubungan antara tanda dan acuannya merupakan hubungan yang sudah terbentuk secara konvensional. Lambang ini adalah tanda yang dibentuk karena adannya konsensus dari para pengguna tanda. Warna merah bagi masyarakat Indonesia adalah lambang berani, mungkin di Amerika bukan. 
Pesan moral pada sebuah film dapat di amati berdasarkan rincian tanda tersebut. Moral merupakan suatu isi dari karya sastra yang ingin di sampaikan oleh seorang pengarang kepada pembaca (Salfia, 2015). Sepanjang sejarah literatur, mayoritas dari karya fiksi bertujuan tidak hanya untuk menghibur tetapi juga untuk menginstruksi, menginformasikan dan meningkatkan pengetahuan audiens atau pembacanya. Hal ini tidak jauh berbeda dengan film. pelajaran-pelajaran moral ini dapat menunjukkan kejujuran, kebaikan kepada orang lain dan lingkungan sekitarnya, kesetiaan dan kerendahan hati.

Kohlberg (Ikrommullah, 2015) mengklasifikasi respon perkembangan moral ke dalam tiga tingkatan, yaitu prakonvensional yang cenderung melakukan sesuatu untuk kepentingan diri sendiri, konvensional yang cenderung melakukan sesuatu untuk orang lain dengan pertimbangan benar atau salah menurut dirinya sendiri, dan pasca-konvensional yang menjunjung nilai tata krama dalam masyarakat.

\section{METODELOGI PENELITIAN}

Jenis penelitian ini adalah penelitian kualitatif deskriptif yakni menggambarkan, mencatat, menganalisis serta menginterpretasikan makna-makna, simbolsimbol yang terkandung dalam film terkait makna pesan moral yang terdapat pada karakter yang ditandai dengan bahasa lisan dan makna pesan moral yang terdapat pada aspek sinematik dalam film Beauty and The Beast.

Sumber data dalam penelitian ini adalah data primer dan data sekunder. Data primer yaitu data yang diperoleh dari objek penelitian yaitu film Beauty and The Beast Live Action. Data sekunder merupakan sumber lain yang dapat mendukung penelitian ini, seperti penelitian semiologi terhadap teori film dan pesan moral pada film yang relevan dengan penelitian ini dan sejumlah buku yang berkaitan dengan teori yang penulis gunakan untuk menjadi referensi penulis.

Dalam penelitian kualitatif, intrumen penelitian adalah peneliti sendiri (Sugiyono, 2014:222). Dalam penelitian ini, setelah penulis mendapatkan data dari sejumlah scene yang telah di cut, penulis menganalisa scene tersebut dan menganalisanya berdasarkan ikon, indeks dan simbol, sesuai dengan teori Charles Sanders Peirce. Selain itu, penulis juga mendapatkan tambahan pertimbangan analisa yang di dukung oleh musik atau dialog dalam scene tersebut. Berdasarkan hasil analisis data ini, maka penulis selanjutnya dapat memberikan sedikit tambahan pengetahuan.

\section{Uji Validitas dan Reliabilitas Data}

Dalam penelitian kualitatif, temuan atau data dapat dinyatakan valid apabila tidak ada perbedaan antara yang dilaporkan peneliti dengan apa yang sesungguhnya terjadi pada objek yang diteliti. Dalam hal ini, penulis memaparkan dengan jelas apa yang di 
tayangkan dalam adegan film Beauty and The Beast Live Action. Tetapi perlu diketahui bahwa kebenaran realitas data menurut penelitian kualitatif tidak bersifat tunggal, mengingat analisa data bukanlah hal yang pasti dan dapat berubah menurut sudut padang peneliti.

\section{Uji Kredibilitas}

Perpanjangan pengamatan yang berarti penulis turun ke "lapangan" untuk melakukan pengamatan kembali dengan sumber data, lalu meningkatkan ketekunan berarti melakukan pengamatan secara lebih cermat dan berkesinambungan, karena dengan cara tersebut maka kepastian data dan urutan peritiwa akan dapat direkam secara pasti dan sistematis. Selain itu, peneliti melakukan pengecekan kembali apakah data yang telah ditemukan itu salah atau tidak. Selanjutnya, penulis melakukan triangulasi dalam pengujian kredibilitas yang diartikan sebagai pengecekan data dari berbagai sumber dengan berbagai cara dan berbagai waktu. Lalu penulis melakukan analisis kasus negatif, yaitu kasus yang tidak sesuai atau berbeda dengan hasil penelitian. Melakukan analisis kasus negatif berarti peneliti mencari data yang berbeda atau bahkan bertentangan dengan data yang telah ditemukan. Selain itu, penggunakan bahan referensi juga sangat di butuhkan dalam penelitian ini. Bahan referensi di sini adalah adanya pendukung untuk membuktikan data yang telah ditemukan oleh peneliti. Mengingat penelitian ini merupakan analisa film, maka penulis menggunakan alat pendukung berupa potongan foto-foto scene dalam film.

\section{Pengujian Transferability}

Transferability merupakan validitas eksternal dalam penelitian kualitatif. Validitas eksternal menunjukkan derajat ketepatan atau dapat diterapkannya hasil penelitian kepada populasi tempat sampel penelitian diperoleh. Nilai transfer ini berkenaan dengan pertanyaan sejauh mana hasil penelitian dapat digunakan dalam situasi yang lain.

Kriteria transferability merujuk pada tingkat kemampuan hasil penelitian kualitatif dapat digeneralisasikan atau ditransfer. Penelitian kualitatif dapat meningkatkan transferabilitas dengan melakukan suatu pekerjaan mendiskripsikan konteks penelitian dan asumsi-asumsi yang menjadi sentral pada penelitian tersebut

\section{Pengujian Dependability}

Kriteria dependabilitas sama dengan reliabilitas dalam penelitian kuantitatif. Pandangan kuantitatif tradisional tentang realibilitas didasarkan pada asumsi replikabilitas (replikability) atau keterulangan (repeatability). Dalam penelitian kualitatif, uji dependability ditempuh dengan cara melakukan audit terhadap keseluruhan proses penelitian. Audit dilakukan oleh auditor yang independen atau pembimbing. 


\section{Pengujian Conformability}

Pengujian conformability dalam penelitian kualitatif disebut juga objektivitas penelitian. Penelitian dikatakan objektif jika hasil penelitian telah disepakati banyak orang. Menguji conformability berarti menguji hasil penelitian, dikaitkan dengan proses yang dilakukan. Bila hasil penelitian merupakan fungsi dari proses penelitian yang dilakukan, dapat dikatakan bahwa penelitian tersebut telah memenuhi standar conformability.

\section{HASIL DAN PEMBAHASAN}

Setelah melakukan penelitian, didapatkan 14 scene yang dianalisa sesuai dengan teori Charles Sanders Peirce dan dibandingkan dengan teori Kohlberg, dengan uraian sebagai berikut:

\section{Scene 1}

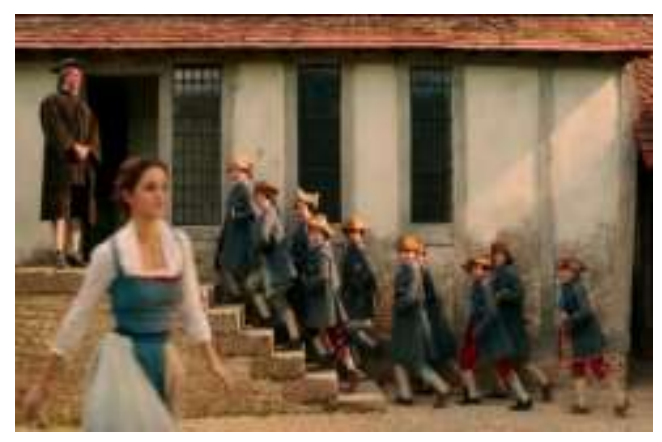

Gambar 4.2. 1 Belle dan anak anak

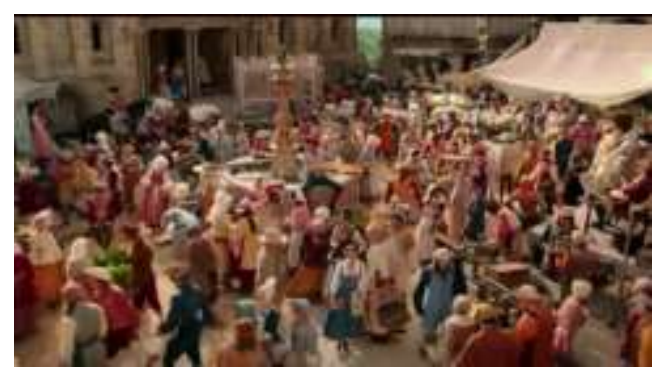

Gambar 4.2. 2 Kerumunan orang

\section{Analisa Visual}

- Ikon : sebuah bangunan, tangga, seorang bapak berpakaian resmi, segerombolan anak-anak berpakaian seragam, Belle, para penduduk desa, tendatenda, gerobak sayuran.

- Indeks :

1. Anak-anak berpakaian seragam menandakan anak-anak tersebut merupakan para murid. Seragam menandakan kesamaan.

2. Sebuah bangunan yang anak di masuki oleh seorang guru dan anak-anak menandakan bahwa gedung tersebut adalah sekolah/tempat menuntut ilmu.

3. Gerobak sayur dan orang-orang dengan nampan sambil berjalan kesana kemari menandakan tempat tersebut adalah pasar pagi

4. Belle berjalan sambil memegang buku menandakan bahwa ia memiliki kebiasaan yang berbeda dengan penduduk desa yang lain.

- Simbol :

1. Sekolah menandakan pendidikan yang pada dasarnya harus di miliki oleh anakanak, sekalipun di desa

2. Keramaian di pasar pagi menandakan rutinitas yang di mulai sejak masih pagi

\section{Analisa Audio}

Lirik lagu tersebut mendeskripsikan dua gambar dari scene tersebut. Belle merupakan seorang gadis yang berbeda 
dengan para penduduk lain di desa tersebut, seluruh penduduk desa mengakuinya. Padahal ia cantik, tetapi di anggap aneh karena ia gemar membaca. Membaca adalah hal yang asing bagi para penduduk desa tersebut. Belle tidak mempedulikan orang-orang yang menatap aneh kepadanya. Gambar dan lagu tersebut mendeskripsikan bagaimana Belle tidak peduli dengan lingkungannya yang cenderung melakukan aktivitas yang sama setiap harinya.

Tanda dalam adegan tersebut menunjukkan bahwa kita tidak perlu merasa aneh atau malu untuk menjadi seseorang yang unik di lingkungan kita, seperti Belle yang tetap dapat menjadi dirinya sendiri yang unik, sekalipun di kelilingi oleh lingkungan desa yang monoton. Hal ini sesuai dengan teori moral Kohlberg pada tahap pra-konvensional, yaitu kepentingan diri sendiri lebih diutamakan daripada pendapat orang lain.

\section{Scene 2}

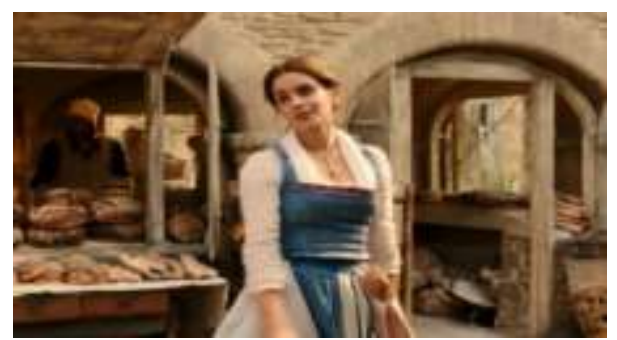

Gambar 4.2. 3 Belle

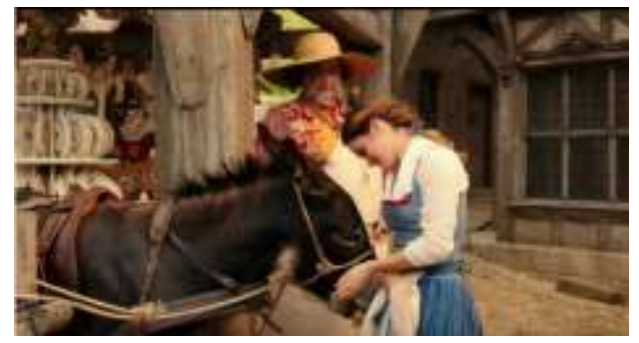

\section{Gambar 4.2. 4 Belle dan peternak}

\section{Analisa Visual}

- Ikon seorang peternak, Belle, kuda, kedai roti

- Indeks :

Belle memalingkan badan ke belakang ketika sedang berjalan menandakan ada sesuatu yang menghentikan dirinya ketika sedang berjalan. Dalam Scene tersebut, yang menghentikannya adalah sapaan selamat pagi dari seorang peternak kepadanya.

- Simbol :

berhenti sejenak, membalikkan badan dan menyapa balik orang yang menyapa kita adalah tanda sopan santun dalam masyarakat.

\section{Analisa Audio}

Berdasarkan percakapan Belle dan si peternak dapat kita lihat bahwa peternak tersebut merasa aneh ketika Belle hendak mencari buku di perpustakaan. Tetapi Belle tidak mempermasalahkan hal tersebut. Ia tetap sopan dan tersenyum kepada si peternak. Tanda tersebut menunjukkan bahwa kita harus tetap sopan kepada siapa saja, termasuk orang yang tidak mendukung hobi atau hal yang kita 
sukai. Hal ini sesuai dengan teori moral Kohlberg tentang norma dalam kehidupan bermasyarakat, yaitu sopan pada orang lain.

\section{Scene 3}

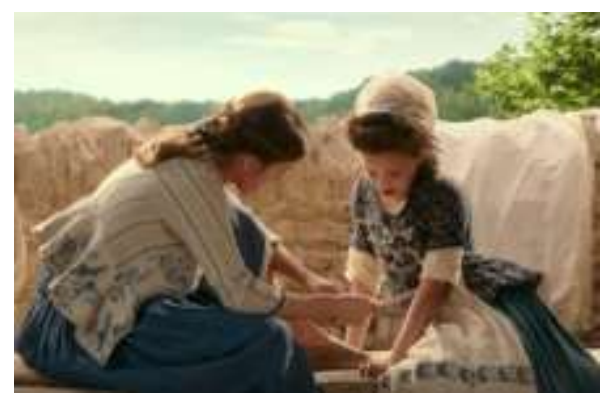

\section{Gambar 4.1. 1 Belle sedang mengajar}

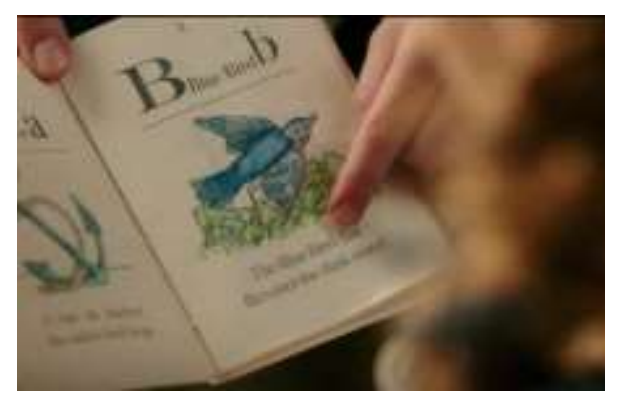

Gambar 4.1. 2 Belle menunjuk buku

\section{Analisa Visual}

- Ikon : Belle, anak kecil, buku, pohon, cahaya matahari

- Indeks :

1. Cahaya matahari dan pohon-pohon menandakan Belle dan si anak kecil sedang duduk di ruang terbuka

2. Belle duduk menunjukkan sesuatu (tulisan) mendandakan ia sedang mengajar anak kecil tersebut untuk melakukan sesuatu (membaca).

- Simbol : buku sebagai simbol ilmu pengetahuan.

\section{Analisa Audio}

Dalam scene tersebut, Belle mengajari si anak kecil untuk melafalkan bacaan "the blue bird that flies over the dark wood" secara sabar. Ia tidak segan-segan membagikan hal yang bermanfaat kepada orang lain di dekatnya. Membaca merupakan sumber pengetahuan dan meskipun membaca adalah hal yang asing di desa tempat Belle tinggal, ia tetap bersedia membagikan kepintarannya kepada orang lain. Tanda tersebut menunjukkan bahwa kita tidak boleh pelit ilmu kepada siapapun juga. Hal ini sesuai dengan teori moral Kohlberg tahap konvensional, yaitu peduli kepada orang lain.

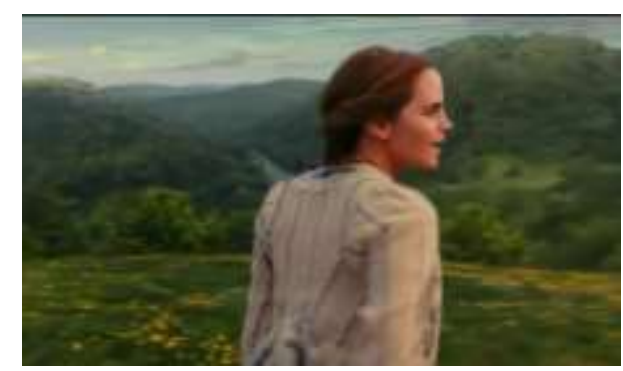

\section{Scene 4}

\section{Gambar 4.2. 5 Belle bernyanyi}

\section{Analisa Visual}

- Ikon : Belle, pepohonan, bukit, bunga matahari, sinar matahari senja

- Indeks :

1. Sinar matahari berwarna jingga menandakan sore hari

2. Memandang desa dari ketinggian, menarik napas sambil tersenyum, 
menandakan sebuah harapan yang hendak di capai

3. Kata 'mereka' dalam lirik lagu tersebut berarti orang-orang di pedesaan yang nyaman melakukan aktivitas yang monoton

- Simbol : Latar tempat adegan yaitu di atas bukit, menjadi simbol bahwa Belle memiliki mimpi yang tinggi di bandingkan dengan orang-orang di pedesaan pada umumnya.

\section{Analisa Audio}

Lirik lagu tersebut mewakili impian terbesar Belle yang ingin memiliki hal atau menjadi seseorang yang luar biasa, melebihi pemikiran umum para penduduk di desa. Nada musik pada lagu yang beritme tinggi, kemudian perlahan rendah dan pelan, menjadi simbol bahwa Belle bersungguh-sungguh pada mimpinya yang berenergi. Tanda tersebut berarti kita tidak perlu takut bermimpi tinggi, karena di setiap waktu kita selalu mempunyai harapan. Hal ini sesuai dengan teori Kohlberg tahap pra-konvensional, yaitu mengutamakan opini diri sendiri.

\section{Scene 5}



Gambar 4.2. 6 Belle takut

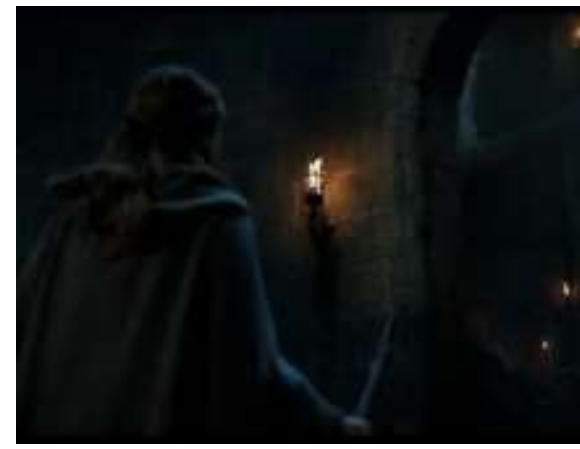

\section{Gambar 4.2. 7 Belle melihat dinding}

\section{Analisa Visual}

- Ikon : Belle, ayah Belle, penjara, lilin di dinding, tongkat kayu

- Indeks :

1. Berteriak kepada musuh sambil mengacungkan kayu menandakan keberanian dalam diri seseorang (Belle).

2. Pantulan cahaya lilin di dinding menandakan ruangan tersebut gelap.

3. Beast menandakan musuh.

- Simbol : Penjara menandakan bahwa seseorang baru saja melakukan kesalahan sehingga ia harus di kurung (ayah Belle). Belle berusaha berunding dengan Beast yang menahan ayahnya di penjara, menandakan sikap seorang anak perempuan yang bersedia berkorban demi menyelamatkan ayah yang di cintainya.

\section{Analisa Audio}

Berdasarkan dialog dalam adegan tersebut, dapat di lihat bagaimana Belle tidak takut menghadapi musuh yang bahkan belum ia lihat rupanya. Ia berteriak langsung dan menyuruh 
musuh (Beast) untuk memperlihatkan diri. Belle bahkan tidak segan-segan mengambil tongkat kayu untuk memukul Beast bila perlu. Dialog yang di dukung dengan indeks tongkat kayu tersebut mempertegas karakter berani dalam diri Belle.

Tanda tersebut menunjukkan bagaimana dalam kehidupan bermasyarakat, orang yang bersalah sudah sepatutnya dihukum, seperti dalam teori moral Kohlberg tahap pasca konvensional.

\section{Scene 6}

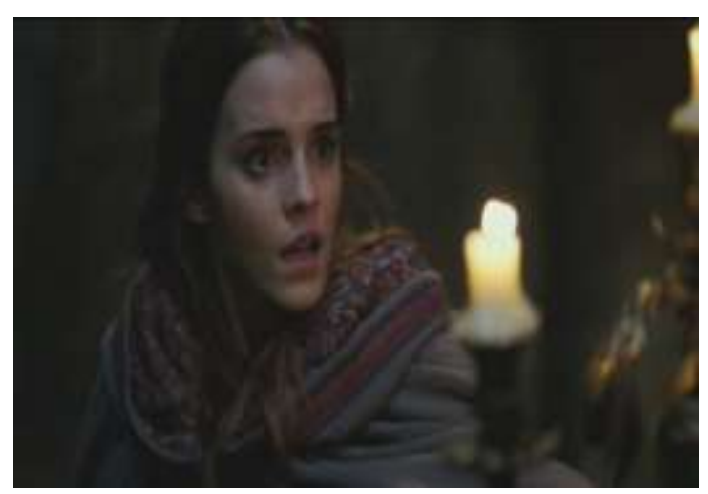

Gambar 4.2. 8 Belle kaget

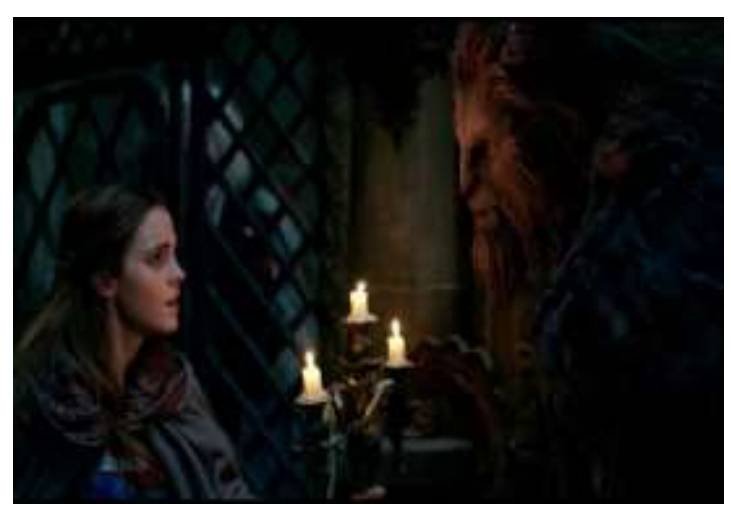

Gambar 4.2. 9 Belle takut melihat Beast

\section{Analisa Visual}

- Ikon : Belle, Beast, lilin, penjara, ayah Belle

- Indeks :
1. Lilin yang bercahaya terang menandakan betapa gelapnya ruangan yang merupakan penjara tersebut.

2. Mata yang terbelalak dan mulut terbuka secara bersamaan menandakan seseorang (Belle) sedang kaget. Ia kaget saat melihat wajah Beast yang menyeramkan di terangi dengan cahaya dari lilin.

3. Tatapan lurus, alis yang naik dan rahang yang tegang menandakan seseorang (Beast) sedang kesal.

4. Seseorang (ayah Belle) berada di balik pintu bergaris-garis/jeruji penjara menandakan orang tersebut sedang di kurung.

- Simbol : Penjara sebagai tanda bahwa seseorang baru saja melakukan kesalahan sehingga ia harus di kurung sebagai hukumannya.

\section{Analisa Dialog}

Sesuai analisa berdasarkan ikon, indeks dan simbol, Belle sangat kaget saat melihat wajah Beast di kegelapan. Tetapi walaupun ia kaget berhadapan dengan makhluk yang menyeramkan seperti Beast, ia tidak berteriak ataupun berlari dari Beast yang merupakan simbol musuh atau masalah pada saat itu. Hal tersebut menandakan bagaimana kita harus berani bertatapan langsung dengan musuh atau masalah yang seburuk apapun, walaupun dalam posisi salah, seperti teori moral Kohlberg tahap pasca konvensional. 
Scene 7

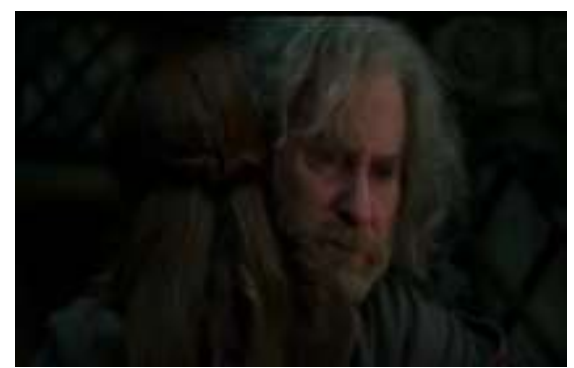

Gambar 4.2. $10 \quad$ Ayah Belle

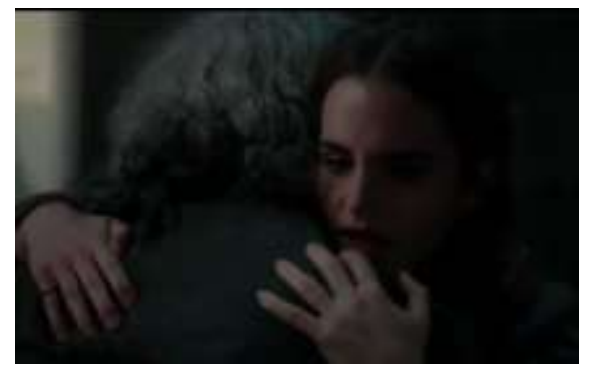

Gambar 4.2. 11 Belle dan ayah berpelukan

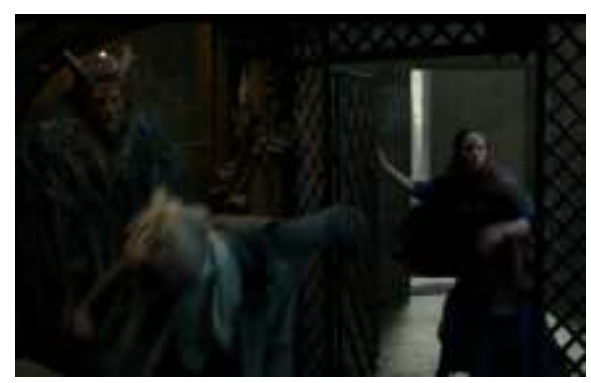

Gambar 4.2. 12. Belle mendorong ayah

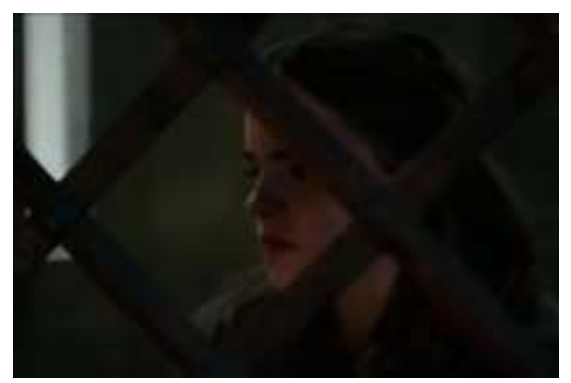

Gambar 4.2. 13 Belle di balim penjara

\section{Analisa Visual}

- Ikon : Belle, ayah Belle, penjara, Beast

- Indeks :
1. Tatapan lurus Belle saat sedang memeluk ayahnya menandakan ia sedang berpikir atau bersiap-siap melakukan sesuatu yang ia rencanakan.

2. Mendorong seseorang mendadak menandakan tindakan tidak terduga. Dalam hal ini Belle harus melakukan hal tersebut karena sebenarnya sang ayah tidak setuju jika Belle menggantikan posisinya sebagai tahanan Beast.

3. Belle segera menutup pintu penjara, menandakan tekadnya sudah kuat untuk menggantikan posisi ayahnya dan membiarkan ayahnya bebas.

- Simbol :

1. Penjara sebagai simbol hukuman

2. Pelukan antara ayah dan anak menandakan kasih sayang

\section{Analisa Audio}

Kalimat yang Belle ucapkan sebelum ia mendorong ayahnya keluar dari penjara "Aku berjanji aku akan kabur" secara tidak langsung mewakili tindakan yang ia lakukan berikutnya. Kalimat tersebut dapat di pahami sebagai kalimat pengganti dari "jaga diri baik-baik ayah, biarkan aku menggantikan hukuman ayah". Tanpa ragu, Belle mendorong ayahnya keluar dan menutup pintu penjara segera. Tindakan tersebut menandakan sikap yakin dan berani dalam diri Belle. Tanda yang ditunjukkan dalam adegan tersebut artinya dalam mengambil sebuah keputusan besar, kita 
harus yakin dan bertekad kuat, apalagi jika keputusan yang kita ambil tersebut berhubungan dengan keselamatan orang yang kita kasihi. Perilaku ini memiliki ciri yang sama seperti teori Kohlberg tahap prakonvensional.

\section{Scene 8}



Gambar 4.2. 14 Beast

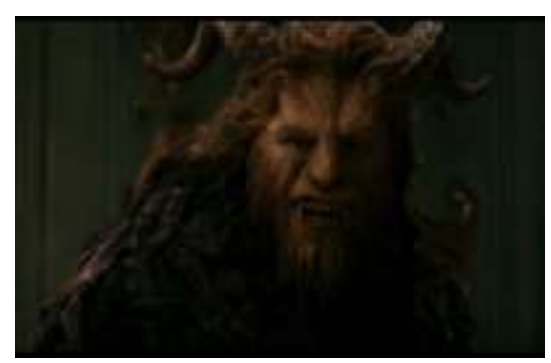

Gambar 4.2. 15 Beast menyeringai

\section{Analisa Visual}

- Ikon : Beast, Lumiere, Cogsworth, Mrs Pots

- Indeks :

1. Melebarkan bibir serta memperlihatkan bibir menandakan senyuman. Tetapi dalam Scene tersebut, mata Beast tidak berbinar. Alis Beast terlihat kaku. Ekspresi tersebut menandakan Beast tidak benar-benar tersenyum dari hati.

2. Lumiere mundur sejenak sambil mengangkat tangan dan tegang saat melihat senyuman Beast tersebut. Hal tersebut menandakan ia ngeri melihat senyuman Beast.

- Simbol : senyum sebagai simbol dari hati yang baik dan ramah.

\section{Analisa Audio}

Lumiere meminta Beast untuk latihan memberikan senyum yang tulus sebelum Belle membuka pintu. Tetapi karena tidak tulus, senyuman Beast malah sangat mengerikan. Selain itu, di karenakan Beast kasar dan marah, Belle justru tidak berniat menemuinya. Dalam cuplikan gambar pada scene tersebut, dapat di lihat bagaimana senyuman Beast yang terlihat terpaksa. Meskipun bibir Beast terbuka lebar, dahi Beast menyernyit dan matanya tidak berbinar. Ekspresi tersebut bukanlah ekspresi senyuman seseorang yang tulus. Ia tersenyum paksa hanya untuk membuat skenario seolah-olah ia tersenyum manis. Tanda tersebut menunjukkan bahwa seseorang tidak dapat menyembunyikan ketidaktulusan dalam senyuman. Beast cenderung egois, seperti dalam teori Kohlberg tahap prakonvensional.

\section{Scene 9}

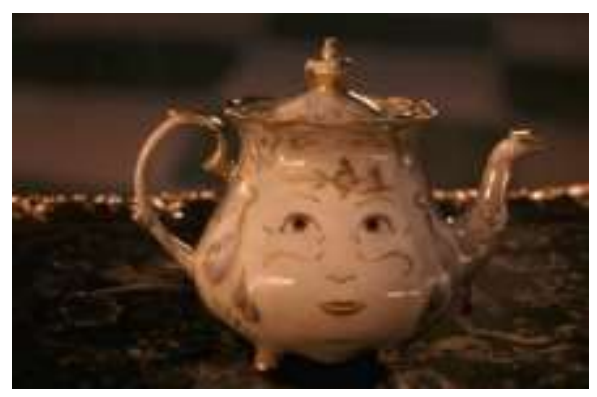

Gambar 4.2. 16 Mrs Pott 


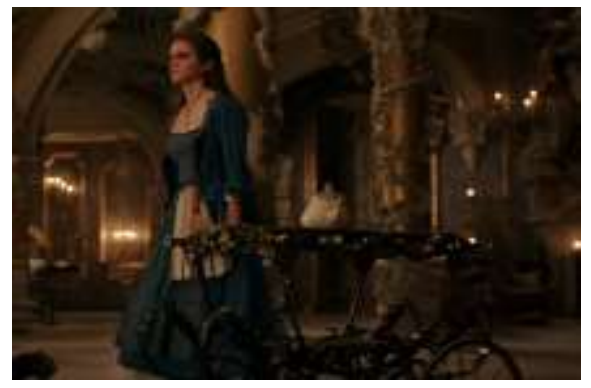

Gambar 4.2. 17 Belle

\section{Analisa Visual}

- Ikon : Mrs Pot, Belle

- Indeks :

1. Mengerutkan alis menandakan seseorang bersedih, bingung atau tidak percaya. Dalam scene tersebut Belle mengerutkan alis karena dia mengingat Beast tidak memperbolehkannya makan apapun kecuali jika Belle bersedia makan bersama Beast.

2. Memutar bola mata sambil berkata "heh" berarti seseorang sedang menyepelekan keadaan. Dalam Scene tersebut Mrs Pots menyepelekan perkataan Beast yang terngiang-ngiang di benak Belle. Maksudnya adalah perkataan Beast tersebut tidaklah penting.

- Simbol : mimik wajah atau tarikan napas dalam adegan menjadi simbol perasaan atau pikiran si tokoh. Dalam hal ini mimik wajah Mrs Pots menjadi simbol bahwa perkataan Beast tidak penting.

\section{Analisa Audio}

Dalam percakapan Mrs Pots dan Belle, kalimat Mrs Pots "orang selalu berkata sembarangan saat sedang marah" menandakan maksud yang sebenarnya yaitu "Kau tidak perlu mencemaskan perkataan Beast, karena dia hanya asal bicara saat sedang marah". Maka dapat di simpulkan bahwa kita tidak perlu mempermasalahkan perkataan orang yang sedang marah. Biasanya orang yang marah mengeluarkan kata-kata kasar yang sebenarnya tidak ia maksudkan, sehingga apapun yang di katakan oleh orang yang marah sebaiknya tidak usah terlalu di pedulikan. Hal ini berarti yang terpenting adalah diri sendiri, seperti teori moral Kohlberg tahap pra-konvensional.

\section{Scene 10}



\section{Gambar 4.2. 18 Belle dan Lumiere}

\section{Analisa Visual}

- Ikon : Belle, Lumiere, ruangan remang yang luas

- Indeks :

1. Lumiere berdiri tegak, menyilangkan tangan kiri ke punggung sambil melebarkan tangan kanan, menandakan sikap hormat seorang pelayan yang mempersilakan tamunya untuk duduk. 
2. Senyuman Belle menandakan perasaan senang karena di sambut dengan baik

- Simbol : senyuman sebagai tanda bahwa dirinya merasa senang karena di sambut dengan baik

\section{Analisa Audio}

Lirik lagu yang di nyanyikan Lumiere dalam Scene tersebut mengekspresikan bahwa kehormatan terbesar dari seorang pelayan adalah untuk menjamu tuan atau tamunya agar dapat menikmati makan malam yang mengesankan. Lagu tersebut menggambarkan bagaimana bangganya Lumiere dan kawankawannya untuk menjamu Belle yang merupakn tamu istimewa di istana tersebut. Tanda tersebut menunjukkan bahwa kita harus tulus dalam memberikan jamuan atau keramahan kepada tamu atau orang yang mendatangi kediaman kita, karena menjamu tamu berarti kita menghargai kedatangan tamu tersebut, sekaligus menjadi simbol kehangatan dirumah kita sendiri. Adegan ini mengandung unsur peduli dengan orang lain, seperti teori moral Kohlberg tahap konvensional.

\section{Scene 11}

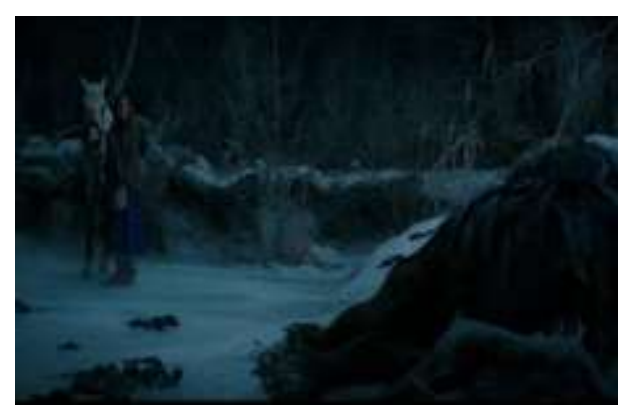

Gambar 4.2. 19 Beast jatuh

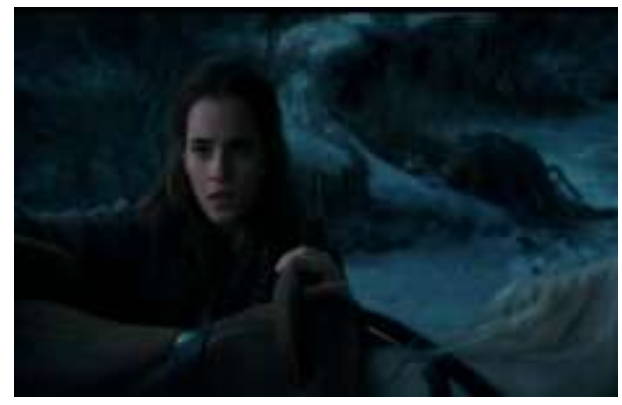

Gambar 4.2. 20 Belle bingung

\section{Analisa Visual}

- Ikon : Belle, Beast, hutan gelap, salju, kuda

- Indeks :

1. Salju menandakan suhu di hutan yang sangat dingin

2. Hendak menaiki kuda menandakan Belle sebenarnya ingin pergi, tetapi ia menghela napas dan menyernyitkan dahi, menandakan adanya perasaan bersalah jika ia meninggalkan Beast yang telah menyelamatkan dirinya.

- Simbol : terbaring lemah di tanah menandakan seseorang terkulai lemas tak berdaya. Dalam Scene tersebut, Beast hampir pingsan akibat berkelahi melawan para serigala.

\section{Analisa Audio}

Tidak ada percakapan antara Beast dan Belle dalam Scene tersebut, tetapi Belle sempat berbisik kepada Beast untuk berdiri agar ia dapat membawa Beast ke istana. Dari cara Beast mengatakan, ada intonasi yang menandakan bahwa dirinya khawatir terhadap Beast, padahal sebelumnya ia berniat pergi 
karena Beast telah kasar dan membentaknya. Namun Belle tetap bersedia membantu Beast yang tak berdaya. Tanda dalam scene tersebut menunjukkan bahwa kita harus senantiasa tulus dalam menolong orang lain, walaupun orang tersebut mungkin pernah berperilaku buruk kepada kita. Ciri ini terdapat pada teori Kohlberg tahap konvensional.

\section{Scene 12}

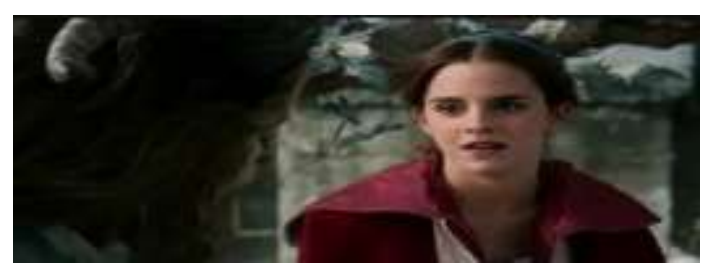

Gambar 4.2. 21 Belle berterimakasih

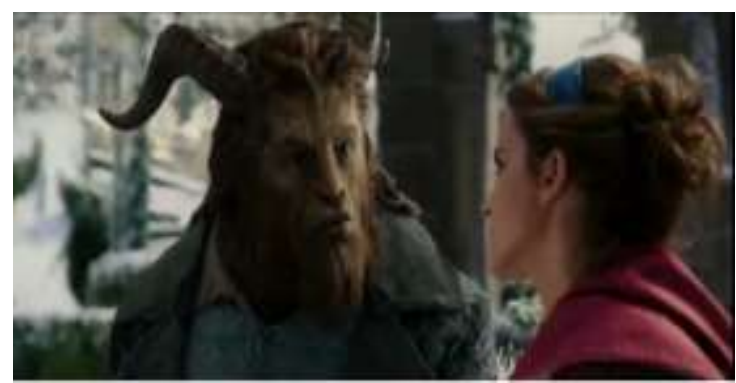

\section{Gambar 4.2. 22 Beast berterimakasih}

\section{Analisa Visual}

- Ikon : Belle, Beast

- Indeks : tatapan antar mata yang tulus menandakan keseriusan atau ketulusan saat mengucapkan kata-kata

- Simbol : ucapan terimakasih adalah bentuk sopan santun dalam masyarakat untuk menghargai perbuatan orang lain kepada diri kita

\section{Analisa Audio}

Percakapan dalam scene tersebut merupakan percakapan dimana Belle dan Beast saling mengucapkan terimakasih atas kejadian di hutan, dimana Beast menyelamatkan Belle dan Belle juga menyelamatkan Beast yang terluka karena di gigit oleh kawanan serigala. Meskipun samasama saling membenci sebelumnya, tetapi perbuatan baik orang lain haruslah di apresiasi, atau setidaknya di beri ucapan terimakasih. Terbukti, sejak kejadian tersebut, Belle dan Beast berteman dengan baik.

Tanda dalam adegan tersebut memberi pesan bahwa kita jangan pernah lupa berterimakasih dengan siapapun yang sudah berbuat baik kepada kita. Sekalipun watak seseorang itu buruk, hargailah setiap perbuatan baik yang di lakukan orang tersebut kepada kita. Berterimakasih pada kebaikan orang lain memenuhi ciri umum dalam hidup bermasyarakat, yaitu tahap pasca konvensional dalam teori Kohlberg.

\section{Scene 13}



Gambar 4.2. 23 Belle panik 


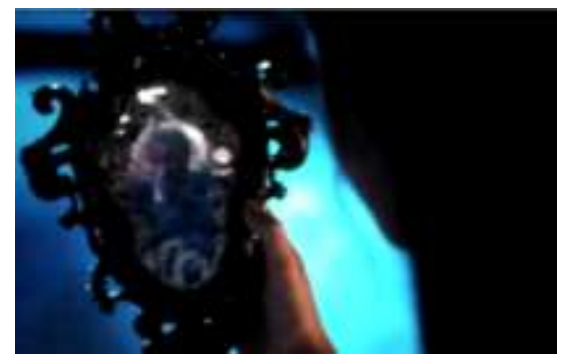

Gambar 4.2. 24 Cermin ajaib

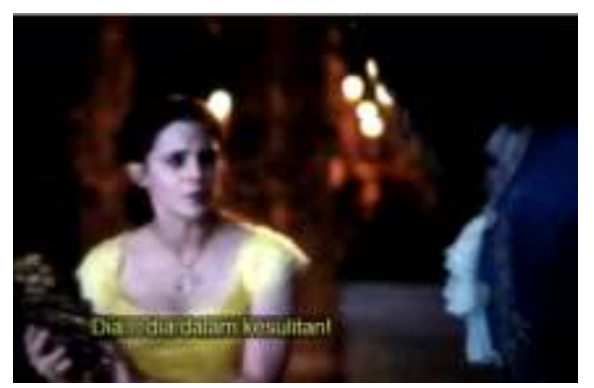

Gambar 4.2. 25 Belle ketakutan

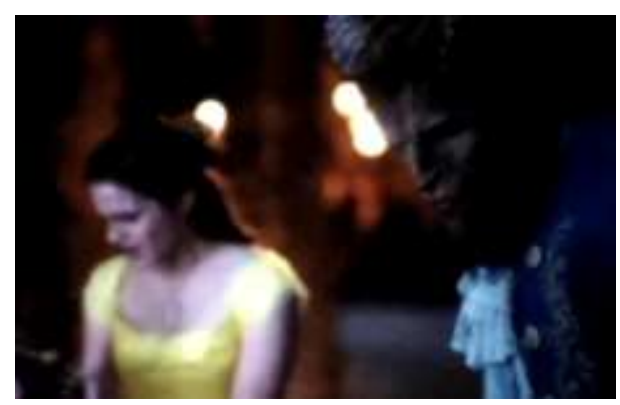

Gambar 4.2. 26 Beast sedang bingung

\section{Analisa Visual}

- Ikon : Beast, Belle, cermin ajaib, bayangan ayah Belle dalam cermin

- Indeks :

1. Melebarkan mata dan mulut ternganga menandakan seseorang sedang kaget

2. Mengerjapkan mata, menyernyitkan alis, menandakan seseorang yang sedang panik karena melihat kejadian yang tidak di sangka

- Simbol : menundukkan kepala sambil menyernyitkan dahi menandakan seseorang sedang sedih atau berpikir keras.

\section{Analisa Audio}

Dalam dialog scene tersebut, Belle panik karena melihat ayahnya sedang dalam masalah. Beast tidak terlalu banyak melakukan dialog karena pikirannya kacau, memikirkan apa yang harus ia lakukan untuk Belle. Tanpa berpikir lebih lama lagi, ia mengambil keputusan untuk membebaskan Belle agar Belle dapat menolong ayahnya yang sedang dalam kesulitan. Padahal, Beast sudah mempunyai rencana untuk menyatakan cinta kepada Belle dan membebaskan dirinya dari kutukan penyihir jahat. Tetapi tanpa memikirkan kepentingan dirinya sendiri, Beast justru melepas Belle pergi demi kepentingan Belle sendiri. Beast lebih memikirkan kepanikan Belle daripada kepentingannya sendiri.

Tanda tersebut menunjukkan bahwa besarnya rasa cinta seseorang dapat di lihat dari seberapa besar ia mengutamakan kepentingan orang yang dicintainya di bandingkan dengan dirinya sendiri, seperti Beast yang menyampingkan kepentingan dirinya sendiri dan malah melepas Belle pergi demi kebaikan Belle dan ayahnya. Hal ini sesuai dengan teori Kohlberg tahap konvensional. 


\section{Scene 14}

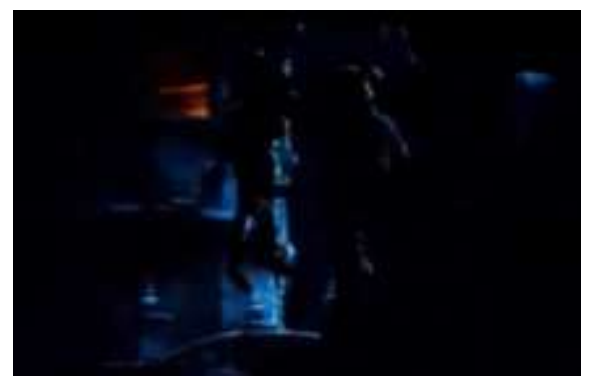

\section{Gambar 4.2. 27 Gaston di hukum}

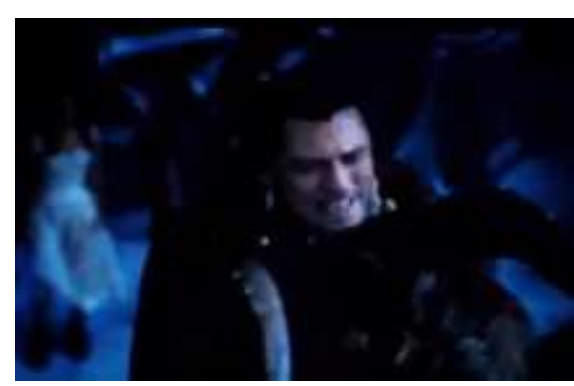

Gambar 4.2. 28 Gaston memohon ampun Analisa Visual

- Ikon : Beast, Gaston, atap istana

- Indeks :

1. Mencekik sebagai cerminan perasaan ingin membunuh menandakan perasaan benci

2. Alis yang tegang, tatapan mata yang tajam dan rahang yang tegang menandakan seseorang yang sedang sangat marah dan benci

- Simbol : perkelahian merupakan bentuk permusuhan yang di praktekkan sebagai bentuk amarah satu sama lain. Dalam Scene tersebut, perkelahian melibatkan adegan mencekik, yang menandakan batas kebencian yang amat dalam.

\section{Analisa Audio}

Hal yang dapat di analisa dari percakapan dalam adegan ini adalah ketika Beast mengampuni Gaston. Walaupun Gaston telah membuat ulah yang sangat merugikan Beast, Beast tetap membebaskan Gaston dari hukumannya. Kalimat yang ia katakan memperjelas pengakuan dirinya bahwa sekalipun ia memiliki penampilan buruk rupa yang menyeramkan (Beast), ia tidaklah seburuk rupanya.

Dari tanda dalam scene ini, dapat di tarik kesimpulan bahwa kepribadian seseorang bisa saja berbanding terbalik dengan penampilannya. Seperti Beast yang memiliki penampilan menyeramkan tetapi sangat rendah hati untuk mengampuni Gaston, yang berwajah tampan tetapi sifatnya sangat buruk. Maka, jangan menilai seseorang hanya dari penampilannya saja. Ciri ini ada kaitannya dengan keyakinan diri ketika Beast mengutamakan kebaikan dalam dirinya. Artinya adegan ini ada kaitannya dengan teori moral Kohlberg tahap pra konvensional.

\section{KESIMPULAN DAN SARAN}

Setelah semua scene telah dianalisa, maka dapat di tarik kesimpulan sebagai berikut:

1. Bentuk pesan moral dalam film Beauty and The Beast Live Action terdiri dari pesan visual dan pesan audio. Pesan visual terdiri dari gerak-gerik tubuh pemeran dan mimik wajah. Sedangkan pesan audio adalah 
dialog pemeran dan juga lagu serta musik yang di bawakan dalam adegan film.

2. Makna pesan moral dalam film Beauty and The Beast Live Action meliputi

a. Percaya dan yakin kepada diri sendiri (scene 1, scene 4, dan scene 14)

b. Menghargai kebaikan orang lain (scene 2, scene 10 dan scene 12 )

c. Peduli dengan orang lain atau tidak boleh egois (scene 8 dan scene 13)

d. Tidak segan untuk berbagi atau menolong orang lain (scene 3 dan scene 11)

e. Berani untuk menghadapi rasa takut (scene 5, scene 6 dan scene 7)

f. Tidak mudah tersinggung dengan perkataan orang lain (scene 9)

Setelah melakukan penelitian ini, penulis menyarankan:

1. Kepada para penonton, selain menikmati film sebagai media hiburan saja, cobalah amati beberapa potongan adegan film yang di tonton, karena jika kita memperhatikan dengan seksama, akan terdapat pesan-pesan tersirat yang disampaikan dalam sebuah film.

2. Kepada para produser film, untuk lebih banyak lagi membuat film yang menarik, sehingga film bukan hanya di tonton masyarakat untuk menghabiskan waktu saja, tetapi juga dapat dijadikan sumber pelajaran kehidupan yang berguna
3. Kepada para peneliti semiologi selanjutnya, terutama semiologi dalam film, agar lebih peka terhadap tanda-tanda yang muncul ketika meneliti sebuah film, karena bisa jadi hal-hal kecil yang kita temui di adegan film, terkadang memiliki makna besar yang tidak kita duga sebelumnya.

\section{DAFTAR PUSTAKA}

Ikrommullah, A. (2015). Tahapan perkembangan moral santri mahasiswa menurut lawrence kohlberg, (7).

Imran, H. A. (2015). Penelitian komunikasi pendekatan kualitatif berbasis teks, 2(2), 129-139.

Mufida, R. R. (2015). 312 3, 1(1).

Nawawy, M. (2016). The Signs of a Strongman: A Semiotic and Discourse Analysis of Abdelfattah Al-Sisi's Egyptian Presidential Campaign. International Journal of Communication. https://doi.org/19328036/20160005

Salfia, N. (2015). Nilai moral dalam novel 5 $\mathrm{cm}, 3(15)$.

Sobur, A. (2016). Semiologi Komunikasi (6th ed.). Bandung: PT Remaja Rosdakarya.

Suprapto, T. (2011). Pengantar Ilmu Komunikasi. (Destyan, Ed.) (1st ed.). Yogyakarta: Central Academic Publishing Servicw.

Syarif, S. (2012). Analisis Semiologi Terhadap Pesan Moral Dalam Film Toy Story 3.

Taufik. (2016). Analisis Semiologi Pesan Pendidikan Dalam Film " 3 Idiots" Karya Sutradara Rajkhumar, 4(3), 1527. 
Tseng, C. (2016). Revisiting dynamic space in film from a semiotic 2016(210), 129149. https://doi.org/10.1515/sem-20160050 perspective. Semiotica,

Yoyon Mudijiono. (2011). Kajian Semiologi Dalam Film. Ilmu Komunikasi, 1(1), 123. 